\title{
The Solidum in Solidarity
}

\author{
Simon Derpmann (University of Münster)
}

\begin{abstract}
:
The article looks at competing conceptions of solidarity. The main focus lies on the universality or partisanship that is associated with moral obligations stemming from solidarity. It appears that the reference to a 'solidum', or a uniting commonality, is crucial to understanding solidarity. In the article, solidarity is defended as a morally significant relation that is wider and more inclusive than direct or intimate relations of friendship, love or loyalty, but simultaneously narrower and more exclusive than universal notions of justice or humanity. Due to their basis in uniting communalities, relations of solidarity are normatively dependent, i.e. the moral content of the shared identifications that ground solidarity determine its moral valence.
\end{abstract}

Keywords:

community; identification; partiality; solidarity; universal obligation

\section{Claims to 'Solidarity'}

'Solidarity' is a contested concept, both in social discourse and in moral philosophy. As the term appears in powerful political traditions, references to solidarity invoke strong normative associations. However, as different incompatible notions of 'solidarity' coexist in everyday uses, moral theory is confronted with the task of providing a systematic understanding of the concept that distinguishes and evaluates competing conceptions of solidarity. In the context of moral philosophy, the concept of solidarity ideally contributes to the systematic understanding of multiple facets of moral obligation, thus providing an instrument for reflecting our position in the social world as moral agents.

My take on solidarity in the following focuses on the 'solidum' that is at the etymological root of 'solidarity'. Accounts of the genesis of the relatively young term 'solidaire' appears in French around the middle of the eighteenth century - trace it back to Roman civil law, as Bayertz (1999, p. 3) or Brunkhorst (2005, p. 2) note. In this specific legal context, the obligatio in solidum, a commitment for an entirety or a whole, establishes a collective of debtors whose members are jointly liable for a common financial obligation. Every participant assumes responsibility not only for her individual share, but for the full common debt. The disposition to stand in for others increases the bargaining power of the collective, and thus enables a joint enterprise that could not be taken on by its dissociated individual members. This idea of empowerment stemming from mutual commitment is reflected in contemporary understandings of the social solidarities within labour unions, civil rights organizations or other movements of social empowerment. Thus, it appears plausible to base the systematic moral notion of solidarity on this initial reference to a solidum, a binding common point of reference. While the genesis of a term does not invariably determine its meaning in moral discourse, the reference to a commonality that unites individual persons through a common cause, a defining situation, or a shared history, alludes to a conception of solidarity that fills a specific gap in moral theory (see also Derpmann, 2009, 2018) between the universality of justice or beneficence and the intimacy of friendship, kith, and kin. In this understanding, 'solidarity' may be conceptualized as referring to special obligations within groups that are defined by morally relevant commonalities in identifications. Commitments of solidarity are not rooted in direct personal relations, but rather stem from identifications with shared experiences, ideals, or struggles. In the following, I argue for two claims: that solidarity requires a point of reference that is narrower than the universal realm of moral persons, and that the moral validity of solidarity is normatively dependent. Some forms of partiality towards communal unions may be described as relations of solidarity in a descriptive sense, but the constitution of the common point of reference, the solidum, may render them morally ineffective. This normative dependency, in turn, calls for the identification of basic criteria for legitimate forms of solidarity.

\section{Universal Solidarity}

Solidarity is often conceived as a universal relation that extends to all humans, a form of recognition that connects all moral subjects. However, the idea of a universal solidarity faces similar difficulties as references to universal friendship, universal comradery, or universal allegiance. What significance can my fellowship with you have, if I understand myself to be everyone's companion alike? The unlimited extension of the scope of these forms of moral relatedness eventually renders their original meaning and significance 
empty. I argue that, in the case of solidarity, these difficulties are related to the quality of the 'solidum', or the commonality that is essential to understanding the normative meaning of solidarity. The reference to universal solidarity is misleading in associating solidarity with a point of view that is defined by the regard of others solely as moral subjects, but at the same time it is not fully independent of moral considerations.

A conception of solidarity as a universal relation appears in different accounts of solidarity in moral philosophy. David Wiggins (2006, p. 248; 2009, pp. 257-258) argues that solidarity consists in a responsiveness to others as persons with an ability to discover meaning and value, and to embrace and act on reasons. In this understanding, the perspective of solidarity establishes a fundamental relation that changes the quality of moral deliberation altogether. Wiggins (2009, p. 268) identifies solidarity as "the [...] thing that any human being owes to any or all other human beings, namely the solidum that is presupposed to the ordinary morality of all interaction between human beings." This fundamental moral recognition establishes deontological side constraints, or absolute prohibitions. In this sense, solidarity resembles the Kantian idea of respect for autonomous persons as ends in themselves. But Wiggins (2009, pp. 233-236, pp. 247-249) emphasizes that the fundamental concern for others that he subsumes under 'solidarity' is not merely derivable from reason, but that it is linked to a fundamental moral sentiment.

In a similar argument, Jürgen Habermas (1990, pp. 244-249) distinguishes the fundamental moral demands of justice that are directly based on the principles of discourse from complementary demands of sympathy or care that are based on solidarity. While moral justice substantiates negative obligations, solidarity - the reverse side of justice - requires moral subjects to strive at promoting the welfare of others. Thus, Habermas (1990, p. 244) supplements the discourse theory of morals with the relation of solidarity in order to be able to account for materially rich notions of social relatedness. In this description the 'shared life-context' relevant to solidarity is not economic class, social position, or political stance but society as a whole. So, here we have two conceptions of solidarity that identify the solidum with the realm of morality altogether. Wiggins understands the solidum to refer to the firmness of solidarity by making the relation of solidarity 'the root of the ethical', or the hard core of morality. For Habermas, the solidum is the realm of moral subjects viewed not only as rational subjects, but as consociates.

Arguably, this understanding of the 'solidum', as the recognition of a universal characteristic of persons to develop an evaluative point of view, an ability to find meaning, or their worthiness of sympathy and care, results in an understanding of solidarity that fails to exhaust its potential as a systematic moral concept (see also Derpmann 2014, 2018). There is a widely held alternative understanding of solidarity as a form of special obligation within distinct communities. The figurative fraternity - and sorority - of the French revolution and the comradery of class struggle share a conception of obligations of solidarity that are not obligations towards others as moral subjects but as members of distinct groups striving for distinct aims or devoting themselves to distinct values. In this understanding, solidarity occupies a specific role in moral deliberation. It constitutes a distinct form of obligation that cannot be subsumed under related ideas, such as friendship, loyalty, or companionship. Solidarity resembles these forms of special obligations in its partiality, and with regard to the moral significance of the specific position of the moral subject. Yet, it differs from them in its indirectness, and in its dependency on shared normative convictions. Solidarity can be distinguished from other associative or communal obligations, because it is not grounded in direct personal relations, but on common ideals and shared goals, or identifications. But, in order to be able to understand solidarity in this way, the point of reference of obligations of solidarity is essentially partisan, not universal.

Richard Rorty (1989, p. 124) places the reference to a morally significant 'we' at the systematic core of solidarity, arguing that "the force of 'us' is typically contrastive in the sense that it contrasts with a 'they', which is also made up of human beings." The moral significance of this 'we' is different for the significance that Wiggins or Habermas could also claim to be entailed in the responsiveness to other persons. Based on a description from Simone Weil, Wiggins (2009, p. 250) captures a similar intuition of a normatively significant 'we' or 'us' that requires "to find in another a subject of the kind of consciousness that we ourselves know, or to find 'one of us' - one who may consent or refuse." However, the 'us' in this context is fundamentally different from the communal 'us' that can be argued to be essential to solidarity. The universal 'us' that is rooted the ability of moral subjects to consent or refuse is different, because the normative force of the reference to a commonality is not fully explicable through the neutral identification of a specific property or a capacity of another person. When others are embraced in a spirit of solidarity as fellows, companions, or allies, they are identified through a common morally significant property in agent-relative terms. They figure as 'laid-off workers like me', 'nonbinary like me', 'republicans like me', etc. In these references, it is not the objectively perceived property of the other as being a laid-off worker or as non-binary, or republican that has moral significance, but our commonality of having a property that we deem of particular evaluative significance to ourselves as solidary subjects.

From here, one can see what distinguishes solidarity as a communal recognition from solidarity as universal moral recognition. The moral significance that is missing in accounts of universal solidarity concerns the role of expressions like 'my' or 'our' as irreducible constituents of moral reasons that are indicative of communal obligation. 
The obligation towards one's own community is not an obligation towards a number of persons with certain characteristics that are morally relevant regardless of one's position or perspective. That the respective community is one's own is a part of the content of the obligation that must be captured in order to grasp its moral force. In contrast, Weil's description of 'one of us' sharing the properties and capacities constituting moral subjectivity contains no similar significant reference to a commonality of these characteristics. It is the quality of the characteristics themselves - being a subject 'who may consent or refuse' that establishes the moral requirement of respect, but not their commonality. In contrast, the communal understanding of solidarity entails a reference to a solidum that makes a specific moral difference. In these contexts, the reference to others as fellow whatevers carries an irreducible reflective reference to the solidary agent herself. In order to understand an obligation of solidarity towards co-workers or companions in a political movement, a person determines something meaningful about herself that relates her to others, be it a political struggle or a common identification with a specific way of life, or a pervasive experience. In her contribution to the present issue, Lisa Dillinger underlines that this specific perspective implies that moral subjects must deploy a different theoretical focus in their reflection of their solidarities, because they do not only examine what is morally valuable or obligatory from a neutral objective standpoint, but what aspects of moral significance are justifiably related to their own evaluative views. This makes reflecting on solidarity so fruitful for the context of education in particular and the development of an ethical selfunderstanding in general. By reflecting on solidarities and their potential justification, moral subjects are confronted with the significance and limits of ethical plurality and the inevitable contingency of some of our evaluative commitments and moral relations. This may be of particular importance in those contexts of education in which the potential frictions of universal moral norms with moral commitments that are interconnected with one's selfdevelopment and self-identification come into view. This leads us to a second topic in the characterization of solidarity, namely the evaluation of the normative content of the communal identifications that establish solidarity in this understanding.

\section{Normative Dependency}

In the conception presented above, evaluative commonalities are seen as - at least potentially - morally significant. While one could reconstruct some aspects of the moral significance of solidarity in terms of the epistemic expectations that can be derived from shared social perspectives, the present conception of solidarity is committed to the claim that some commonalities themselves may ground moral relations of solidarity. It is not only that in calling for solidarity subjects are appealing to others that due to their shared social position, they should comprehend what it is like to be a single parent, an unskilled worker, or a person with a nonconformist sexuality, confession, or appearance. While the appeal to a shared epistemic experience of a social issue is of moral relevance, I argue that the commonality of solidarity goes beyond this.

If reasons of solidarity are based on common identifications, i.e. on the shared commitment to evaluations that are deemed essential to one's self-understanding, then some solidarities become doubtful as sources of moral obligations due to the moral refutability of many conceivable identifications. So, solidarity appears to be normatively dependent (see Löschke 2015, p. 52 ff.) in the sense that some relations that may descriptively pass as relations of solidarity do not generate moral obligations due to the objectionability of the underlying commonalities, i.e. due to the content of the constitutive identifications. The mutually recognized commitment of mobsters, white-supremacists or despotic rulers may be descriptively classified as forms of solidarity, just as a promises to hurt or humiliate someone may be described as promises. But this does not mean that they bear moral significance. Not all objects of shared identification may be worth identifying with. So, if the moral validity of solidarity is dependent on the morality of its underlying identifications, are there criteria for legitimate and illegitimate solidarities?

Objections to problematic identifications underlying questionable solidarities primarily concern contemptuous solidarities, and exclusionary forms of solidarity. While it is challenging to provide general criteria for admissible forms of identification that are capable of generating communal obligations of solidarity, some identifications - e.g. among sexists or racists - clearly fail to create a moral bond of solidarity, because of their incompatibility with fundamental moral norms like the recognition of moral subjects as equals, the recognition of persons as ends in themselves, etc. Of course, a reply to this basic rejection of contemptuous solidarities objects that solidarity itself - at least in the definition given above - is designed not to understand moral subjects as equals due to its essential partiality. Is solidarity not immoral by definition due to its exclusive core that is, in turn, derivative of its essential partiality? Solidarity is necessarily partial and - to some extent - exclusive due to the presumed dependency on an identification that establishes a morally significant 'we'. However, some qualifications show that not all forms of solidarity are vulnerable to this objection, at least if it is meant to unavoidably link solidarity to divisiveness and chauvinism.

Partiality is compatible with recognizing others as equals. A person may identify with a conviction of hers and feel especially obliged to those who share this conviction without presuming that others are objectively of a secondary moral status or deserving of a lesser moral recognition. The point in relational obligations like solidarity, friendship, loyalty, or love is that particular others are special to me, not that they are special per se. However, one may object that some 
common forms of solidarity are 'closed' in the sense that they appear to be based on natural features or a confinement to a fixed group. They are not permeable to groups of subjects who are inevitably and immutably conceived as others. If racism or sexism are problematic due to their rationale of a moral distinction based on unchosen characteristics - the 'naturalness' of which is, of course, questionable -, why not the delimitation entailed in the solidarities among women or among persons of color? Should we deny moral relevancy to any club membership that is based on natural features? Note, however, that there is a crucial difference between the rationale underlying racism or sexism and the moral cohesion in the - arguably solidary - movements that respond to racism and sexism. Solidarity within particular social movements derives from a shared conviction - that there should be gender equality or that Black lives matter -, not from a descriptive characteristic. Some aspect of these kinds of solidarities, however, may be based on a shared opposition to being subjected to a social position that serves as a point of reference, and this position may be tied to an experience of discrimination or oppression related to the conferral of racial or sexual categorizations that cannot simply be assumed by others. So, there may be forms of solidary connectedness that require being Black or being a woman, etc. The decisive difference is that these communalities, if they are to be understood in terms of solidarity, do not stem from a given characteristic alone, but from the identification with a social position that may be only fully grasped from the experience of being in this position. So, while solidarity among feminists is not exclusive to women or female persons, the social implication of being female or being a woman in a given society, may warrant an additional layer of solidarity in this context. This leads to another observation regarding the constitution of solidarities.

Solidarities are multilayered. While solidarity is exclusive - in the sense that it requires a conception of those who belong to a group, and those who do not - moral subjects do not typically affiliate with only one single group, but engage with many facets of their social belonging, thus creating overlapping layers of solidarities. In this context, Amartya Sen (2006, pp. 20-24) warns against misunderstanding our identities via 'singular affiliations'. Even supposedly clearly delimited forms of identification turn out to be multilayered. A 'Black Lives Matter'-activist, for instance, may have several identifications that belong to this particular aspect of her self-understanding, and that extend to different circles of potential solidary allies. She may identify as Black, as a person of color, as an African American, as a BLM activist, as the subject of discrimination or oppression, as an enemy of racial injustice, or for that matter as an enemy of social injustice altogether, etc. Thus, although the semantics of solidarity requires a 'we' and a 'they', this does not mean that societies must be conceived as divided into monolithic blocks through the manifestation of solidarities. Rorty (1989, pp. 191-192) convincingly makes this argument for an indirect societal cohesion through the interweaving of multiple solidarities. Thus, while solidarity may be considered as exclusive, the multiplicity of solidarities may nevertheless generate wide reaching forms of social cohesion.

The main takeaway from the preceding observations may be that, even though solidarity is not necessarily problematic qua being a form of communal partiality, the moral reliance on concrete solidarities requires the thorough reflection of the underlying unifying convictions and a readiness for justification and scrutiny of the constitution of the solidum in solidarity. The main work of moral justification in the context of sustaining solidarity lies here, and it is messy work, because it requires of us to figure out our own complex evaluative perspective, the legitimacy of deriving moral reasons from it, and the various circles of subjects with whom we may feel significantly connected above the basic requirements of moral respect. One's solidarities are not as neatly organizable as club membership cards, and the strength of the accompanying obligations varies, especially when they are weighed against competing neutral obligations. Solidarity requires constant reflection upon who we are and which of our experiences, characteristics, or convictions we deem central enough to substantiate and justify special moral relations that go beyond what is owed to every moral subject alike.

\section{References}

Bayertz, K. (1999). Four uses of “solidarity”. In K. Bayertz (Ed.), Solidarity (pp. 3-28). Springer. https://doi.org/10.1007/978-94-015-9245-1_1

Brunkhorst, H. (2005). Solidarity: From civic friendship to a global legal community. MIT Press.

Derpmann, S. (2009). Solidarity and cosmopolitanism. Ethical theory and moral practice, 12(3), 340-353. https://doi.org/10.1007/s10677-008-9150-6

Derpmann S. (2014). Solidarity, moral recognition, and communality. In A. Laitinen, \& A. Pessi (Eds.), Solidarity: Theory and practice (pp. 105-125). Lexington Books.

Derpmann S. (2018). Union's inspiration: Universal health care and the essential partiality of solidarity. Bioethics, 32(9), 569-576. https://doi.org/10.1111/bioe.12444 
Habermas, J. (1990). Justice and solidarity: On the discussion concerning stage 6. In T. E. Wren (Ed.), Studies in contemporary German social thought. The moral domain: Essays in the ongoing discussion between philosophy and the social sciences (pp. 224-251). MIT Press.

Löschke, J. (2015). Solidarität als moralische Arbeitsteilung. Mentis.

Rorty, R. (1989). Contingency, irony, and solidarity. Cambridge University Press.

Wiggins, D. (2006). Ethics: Twelve lectures on the philosophy of morality. Penguin.

Wiggins, D. (2009). Solidarity and the root of the ethical. Tijdschrift voor Filosofie, 71(2), 239-369. https://doi.org/10.2143/TVF.71.2.2038077

\title{
Recommended Citation
}

Derpmann, S. (2021). The solidum in solidarity. On Education. Journal for Research and Debate, 4(10). https://doi.org/10.17899/on_ed.2021.10.4

\begin{abstract}
About the Author
Dr. Simon Derpmann is assistant professor in the Department of Philosophy at the University of Münster and scientific coordinator of a graduate school on Democracy, Human Rights, and Religion. Currently, he works on issues within economic philosophy, especially the idea of ownership in money.
\end{abstract}

